\title{
OS LIMITES DO ESPECÍFICO HISTÓRICO. As relações inter-disciplinares nas Ciências Humanas em livro recente de Ladurie.
}

\author{
VICTOR DEODATO DA SILVA \\ do Departamento de História da Faculdade de Filo- \\ sofia, Letras e Ciências Humanas da Universidade de \\ São Paulo.
}

Velhas de meio século, as preocupações com as relações entre a História e as demais Ciências (1) têm visto seus p̧ontos de vista ganharem terreno sem parar. Consolidando essas tendências surgiu na França coleção que propōe-se, como programa, publicar obras que dèm ênfase às relações inter-disciplinares (2). Dentro dessa linha, pode-se dizer que é difícil conceber trabalho melhor exemplificativo do que o livro dedicado por Ladurie à aldeia de Montaillou no início do século XIV (3).

Essa característica é de tal forma saliente que o leitor pode legitimamente ficar $\mathrm{cm}$ dúvida sobre o seu grau de especificidade histórica e se torna defensável o ponto-de-vista de que a parte mais essencial do conteúdo do livro se enquadra mais propriamente nos domínios da Etnografia, afirgurando-se como marginal aquilo que pode ser considerado como relevando da História. Contudo, essa observação se aplica tão somente à temática, pois trata-se de pesquisa que, considerada a natureza das fontes utilizadas, pressupõe uma sólida formação de historiador, para ser levada a bom termo.

Para melhor comprovar nossa tese, vamos momentaneamente deixar de lado uma série de dados circunstanciais e vamos ao cerne

(1) . - Em relação à França, o famoso grupo dos Annales, constituído ao redor de Marc Bloch e Lucien Febvre, e o Centre International de Synthèse, fundado por Henri Berr, já se inserem claramente nessa linha de cogitaçōes.

(2). - "Bibliothèque des Histoires", edição da N.R.F. - Gallimard.

(3). - LADURIE (Emmanuel Le Roy). - Montaillou, village occitan de 1294 à 1324 . Col. "Bibliothèque des Histoires". Paris, N.R.F. - Editions Gallimard, 1975. 642 páginas "in-80" $(14 \times 22 \mathrm{~cm})$. 
mesmo da obra. O Autor toma uma minúscula comunidade agrária, situada numa região montanhesa de acesso não muito fácil, analisando seu comportamento social, no sentido mais amplo do termo (modos de vida, estratificação social; práticas sexuais; relacionamento familiar, a partir dos mecanismos de circulação feminina, método desenvolvido sobretudo pelo "papa" do estruturalismo, Levi-Strauss; mentalidade; ética; concepções da vida "além-túmulo; etc.), a partir de episódios ocorridos no intervalo de trinta anos. $\mathrm{O}$ isolamento em que viviam os cerca de 200 habitantes da aldeia de Montaillou, situada em região pirenaica oriental, favorecia uma conduta de tal forma avessa às inovações que, não obstante alí chegarem ecos do que ocorria em centros de civilização vizinhos, suas afinidades com as sociedades ditas primitivas acabam por se tornar manifestamente preponderantes. Assim, tanto os caracteres do agrupamento urbano, quanto o tipo de abordagem empregado no seu exame se revelam bem mais típicos da Etnografia, dentro da dimensão que Levi-Strauss emprestou a essa ciência, do que da História.

Caracterizado o essencial do conteúdo do livro, digamos algo a respeito dos aspectos mais propriamente históricos, o que nos permitirá tratarmos, ainda que sucintamente, da parte (preponderante na proporção de no mínimo oitenta por cento) qualificada como etnográfica. Como é ressaltado mais de uma vez pelo Autor, o trabalho deve a sua existência ao zelo inquisitorial, lúcido e sistemático, de um prelado, o bispo de Pamiers, Jacques Fournier, posteriormente guindado ao pontificado com o nome de Bento XII, e que, propondo-se a extirpar a heresia cátara, ou albigense, de uma aldeia pirenaica, Montaillou, com extraordinária habilidade interrogativa, soube fazer falar os membros da aludida comunidade e, o que é ainda mais importante para o pesquisador atual, deu-se ao trabalho de constituir um registro integral e fidedigno, descontado o fato de os depoimentos terem sido traduzidos do $o c$ vernáculo para o latim. E é nas indicações sobre os mecanismos de difusão do catarismo, bem como ao seu combate, com toda a carga de intervenção externa no agrupamento citado- da parte da Igreja e da Coroa francesa, num plano mais efetivo, e dos Condes de Foix, representantes da autoridade regional tradicional, por algum tempo eficientes no apoio à resistência local às ingerências estranhas, mas aos poucos recuando para um plano assaz apagado que reside a dimensão mais especificamente histórica da obra, pois, como pode ser lido no capítulo conclusivo, as mesmas abstraidas, a

“... carrière de ce village s'échelonne ... sans Histoire, mais non sans histoires, depuis sa fondation (aux temps carolingiens?) jusqu’à notre époque..." (página 624). 
O método utilizado foi o de decompor o extremamente detalhado depoimento e a partir daí reconstituir o modo de vida dos habitantes da comunidade e seu relacionamento, tanto interno quanto externo, nos aspectos mais variados possíveis, e que foram acima enumerados (ainda que não totalmente). Na primeira parte - "Écologie de Montaillou: la maison et le berger" — o habitat e os habitantes nos são apresentados e nela são opostos os dois tipos de vida mais característicos dessa sociedade, o camponês sedentário, com a domus como o fator de enquadramento, e o pastor transumante, solitário (solteiro por sistema...) e sem conforto, mas livre, e fazendo dessa liberdade a sua riqueza. Mas outros tipos de oposições são configurados: adultos e crianças, jovens e velhos, homens e mulheres, autoridades locais e externas, heréticos e ortodoxos, etc., com esse gênero de dialética percorrendo todo o volume. A casa (domus), mais do que a terra ou a linhagem, é apresentada como o ponto de referência, na apresentação dos personagens, onde a preocupação de caracterização é tão acentuada que, em muitos momentos, nos sentimos próximos da ficção romanesca do século XIX, Flaubert e Balzac seriam bons exemplos, aspecto ao qual retornaremos ulteriormente. Aquí destaca-se o cura da aldeia, apropriadamente chamado Pierre Clergue, do qual diz-se:

“... Les mots manquent pour décrire l'ubiquité perverse de ce personnage, à la fois cathare, mouchard et paillard..."

e que, sabendo situar-se na posição de intermediário (mas do tipo "quinta coluna"!) entre a repressão católica e a população - subterrânea mas convictamente herética - em troca da proteção fornecida, teve a sua posição de liderança por ela reconhecida. Em outra passagem, Pierre Clergue é qualificado de "Jean-Jacques Rousseau montanhês", devido à sua propensão para filosofar em torno das relações sociais, mas, ainda mais legitimamente, ele pode lembrar um personagem saído dos romances de Dostoiewsky...

Caracterizados o habitat e os habitantes, o que já representa uma reconstrução a partir da reordenação de dados do registro inquisitorial, na segunda parte - "Archéologie de Montaillou: du geste au mythe" - é efetuada uma investigação em profundidade, sendo os diversos níveis do comportamento individual e coletivo dos habitantes de Montaillou equiparados a camadas do solo irregularmente sotopostas, de acordo com o método preconizado por Foucaut e por ele classificado, metaforicamente, como "arqueológico". Com mais de 400 páginas, é a mais importante parte da obra e nela, tanto o próprio registro, quanto a primeira parte do volume são decompostos e recompostos em novas combinações, como pedras de mosaicos. Com- 
portamentos, relações culturais, controvérsias religiosas, concepções, etc. são tratados sucessiva e correlativamente, abundando dados importantes, constituindo contribuição inegável ao melhor conhecimento do período, por mais de una vez desmentindo lugares-comuns da historiografia corrente. Por exemplo, quando se fala dos trovadores como inventores das formas modernas do amor, verdadeiro chavão consagrado e que o presente trabalho ajuda a desmistificar, já que o Autor encontrou casos inequivocos de afeição profunda entre homem e mulher, isso num meio que, embora localizado não muito longe dos centros de cultura troubadour, e numa época posterior ao pleno florescimento do mesmo, certamente não sofreu nenhuma influência direta ou indireta dele, configurando-se como mais correto supor que os referidos aedos antes elaboraram fórmulas de expressão do sentimento amoroso, sem criarem o sentimento propriamente dito (e, de resto, na mitologia, tradição e história da Antigüidade Clássica também não são tão raros os exemplos de inclinação prơ̂unda). Outra nocão corrente desautorada é a que atribui às comunidades rurais, sobretudo as mais isoladas, exatamente o caso de Montaillou, a condições de redutos de práticas e crenças pagãs, de que não se localizou nenhum exemplo inequíivoco (ainda que sobrevivências extremamente difusas possam ser admitidas), e que, se existissem, não deixarian de ser detectadas, dada a natureza do inquérito e a habilidade inquisitcrial do seu responsável. E como esses, muitos outros exemplos poderian ser evocados.

Mas, o fato de nos limitar-nos a dar exemplos do interesse propriamente histórico da obra e acentuarmos seu caráter acentuadamente etnográfico, não implica em dissuadir os historiadores, e interessades por História em geral, de sua abordagem, visto que estamos na era das relações científicas inter-disciplinares, as quais nos obrigam a ampliar constantemente nossas áreas de interesse. Além disso, trata-se de livro suscetível de interessar qualquer pessoa culta, de tal forma absorvente é a sua leitura, que não raro, como já acentuamos anteriormente, o aparenta com a literatura de ficção. E já que falamos em ficção, e visto que prometemos voltar a esse aspecto, encerraremos esta nossa resenha, não muito convencionalmente talvez, com una sugestão para universitários sedentos de temas de tese, e que, pela sua inter-disciplinaridade de caráter, pode tanto interessar a estudiosos de Literatura, historiadores e etnógrafos, e que não consideramos para nós próprios por se referir a uma fase histórica situada fora do nosso período de eleição, a Idade Média: abordar a Comédie Humaine de Balzac de forma análoga à adotada por Ladurie no estudo em exame.

A grande objeção seria a de que, ao contrário do Registre de Jacques Fournier, a Comédie é obra de ficção. Mas, ao mesmo tem- 
po, aí reside também a sua força. Com efeito, a análise das estruturas de parentesco, gestos, relações familiares, etc., numa sociedade ineqüivocamente civilizada e "aberta" - diversamente do que ocorria com a Montaillou do século XIV - com documentação de arquivo é literalmente impossível. Tal se deve, entre outros fatores, à interpenetração de normas legais, formas de comportamento transitórias (em vista das transformações econômicas, institucionais, políticas, etc. a que essas sociedades estão sujeitas) e, sobretado, obediência a convenções resguardadoras das conveniências e aparências (em particular na ausência de um inquisidor), que mascaram o sentido profundo das relações sociais. Nesse sentido, o ficcioništa não se sente tolhido pelas peias que inibem as fontes usualmente utilizadas pelos pesquisadores das Ciências Humanas, revelando-se, a esse respeito, excepcional a sensibilidade revelada por Balzac, capaz mesmo de substituir os mais complexos circuitos de computação eletrônica e suas respectivas equipes de analistas e programadores.

Apenas para dar um exemplo: quando, em Père Goriot, a viscondessa de Beauséant oferece seu baile de despedida (caso um tal evento pudesse ter ocorrido na realidade, é forçoso admitir), nem a leitura dos jornais da época, nem o exame de quaisquer outros documentos permitiria detectar o significado do evento. Sem dificuldade, no entanto, o romancista nos esclarece que a festa em questão representava o adeus de sua promotora ao mundo, devido ao casamento de seu amante, o Marques de Ajuda, enquanto o Visconde de Beauséant, o marido legal, assiste a tudo consternado, por ser amigo sincero da esposa, mas impotente. Assim, num relance, é feita luz sobre a naturalidade com que, na alta sociedade de então, era encarada a existência de laços paralelos ao matrimônio e a situação, ainda que romanesca, nem por isso é menos reveladora de certos mecanismos das relações sociais.

O próprio Balzac, aliás, reprochava aos historiadores o descaso para com a história dos costumes e manifestava a intenção de concorrer com o Registro Civil, o que torna sua obra particularmente apta à utilização como fonte de pesquisa sociológica, etnográfica, etc. O que, no final das contas, é menos inćdito do que pode parecer à primeira vista, pois um bom número de sociedades do passado tem sido objeto de reconstituição a partir de fontes puramente literárias (a Grécia homérica e a Escandinávia anterior à cristianização são bons exemplos).

Embora admitindo não se tratar de tarefa facil, entendemos que a partir da Comédie Humaine poder-se-ia realizar uma sugestiva "ar- 
queologia" da sociedade francesa da primeira metade do século dezenove. A última vez que frequientamos a obra ocorreu-nos a possibilidade desse empreendimento, cujo interesse nos parece óbvio, e o livro de Ladurie convenceu-nos de sua viabilidade. Coisas da inter-disciplinaridade... 